\title{
Influence of neonatal screening and centralized treatment on long-term clinical outcome and survival of CF patients
}

\author{
M.E. Mérelle*, J.P. Schouten\#, J. Gerritsen`, J.E. Dankert-Roelse*
}

Influence of neonatal screening and centralized treatment on long-term clinical outcome and survival of CF patients. M.E. Mérelle, J.P. Schouten, J. Gerritsen, J.E. Dankert-Roelse. (C) ERS Journals Ltd 2001.

ABSTRACT: After an experimental neonatal screening program for cystic fibrosis (CF) from 1973-1979, a follow-up study took place from 1980-1997. Patients were treated at specialized centres $(C)$ or at local hospitals (non-C). Aims of the study were: 1) to determine whether the previously reported benefits from screening persisted with time and after adjustment for confounding variables; and 2) to investigate whether centre treatment was associated with improved prognosis of $\mathrm{CF}$ patients.

Prognosis of patients detected by screening $(S ; n=24)$ was compared with patients detected clinically, born during (non-S; $n=29$ ) and after the screening programme (post$\mathrm{S} ; \mathrm{n}=39$ ). In addition, prognosis was compared between $45 \mathrm{C}$ and 47 non-C patients. Multivariable regression analysis was used to compare survival and mixed-effects model regression analysis was used to compare clinical outcome between patients. The analyses included the variables screening, centre treatment, sex, meconium ileus and genotype.

$\mathrm{S}$ patients had a significantly smaller decline in forced expiratory volume in one second (FEV1) (difference $+\mathbf{2 . 7 4} \%$ predicted) and significantly lower immunoglobulinG (IgG) levels (difference $-473.69 \mathrm{mg} \cdot \mathrm{dL}^{-1}$ ) than non-S patients until $12 \mathrm{yrs}$ of age. At 12 yrs of age, vital capacity was significantly higher in $S$ patients than in non-S patients (difference $+362.79 \mathrm{~mL}$ ). Survival seemed to be best for $\mathrm{S}$ patients compared to both non-S and post-S patients. Post-S patients were significantly heavier (difference in SD weight +0.77 ), had a significantly smaller decline in $\mathrm{FEV} 1$ (difference $+\mathbf{2 . 8 0} \%$ pred) and lower IgG levels (difference $\mathbf{- 4 5 3 . 0 4} \mathrm{mg} \cdot \mathrm{dL}^{-1}$ ) than non-S patients until 12 yrs of age. $\mathrm{C}$ patients had a significantly improved survival (relative risk (RR) $0.18,95 \%$ confidence interval 0.05-0.57) than non-C patients.

Early diagnosis through neonatal screening leads to better preservation of lung function in the long term in cystic fibrosis patients. Management of cystic fibrosis patients in specialized centres improves survival.

Eur Respir J 2001; 18: 306-315.
*Dept of Paediatrics, Medical Centre Vrije Universiteit, Amsterdam, "Dept of Epidemiology and Statistics, University of Groningen, "Dept of Paediatrics, University Hospital Groningen, the Netherlands.

Correspondence: J.E. Dankert-Roelse, Dept of Paediatrics, Medical Centre Vrije Universiteit, PO Box 7057, 1007 MB Amsterdam, the Netherlands. Fax: 31204440849

\section{Keywords: Centre treatment}

cystic fibrosis

follow-up study

lung function

neonatal screening

Received: September 121999 Accepted after revision April 172001

This study was supported by ZorgOnderzoekNederland (ZON) grants $28.566,28.566-1$ and 28.566-2.
Pulmonary disease is the major cause of morbidity and mortality in cystic fibrosis (CF). Shortly after birth, the lower airways of most $\mathrm{CF}$ patients become colonized with bacteria which leads to lung infection and inflammation [1]. Bacterial lower respiratory tract infections in $\mathrm{CF}$ are associated with significant pulmonary deterioration but are amenable to antibiotic therapy at an early stage, resulting in clearance of pathogens and reduction of inflammation [2]. Therefore, early diagnosis may favourably influence prognosis of patients with $\mathrm{CF}$ as a result of early intervention, which may prevent or postpone early irreversible damage of the airways.

Any proof of the medical benefit of an early $\mathrm{CF}$ diagnosis through neonatal screening requires studies with many years of follow-up, given the relatively long life span of patients with CF. Consequently, patients with CF may have been denied an effective form of intervention for a long time while awaiting conclusive results of randomized, controlled trials of neonatal screening for CF [3-5]. The effectiveness of neonatal screening for $\mathrm{CF}$ can also be assessed by nonrandomized, controlled studies with a long follow-up period, focusing on important clinical outcome measures such as pulmonary status [6].

In the present 17-yr follow-up study of patients with $\mathrm{CF}$, earlier observations were extended over a longer period and a greater number of patients. In contrast to previous reports [7, 8], data in this study were analysed on an intention-to-screen basis and analyses were adjusted for possible confounding variables, such as centre treatment, sex, meconium ileus, and genotype. CF care is probably best provided in specialized centres because of the all-round management, although few data exist to prove this assumption.

The aims of this study were: 1) to determine whether the previously reported benefits from neonatal screening [7,8] persist with a longer duration of follow-up and after adjustment for several potential biases; and 2) to investigate whether centralized treatment was associated with improved prognosis of patients with $\mathrm{CF}$. 


\section{Methods}

\section{Study design}

The design of this study has been described in detail elsewhere [8]. In summary, a clinical follow-up study of patients with CF was performed from April 1980April 1997, after an experimental neonatal screening programme for CF. Screening for CF was carried out in a geographically defined area in the north of the Netherlands from March 1973-March 1979, using the determination of the albumin content of meconium [9]. Of all neonates born in this area, $45 \%$ were involved in the screening programme. The organizations caring for mother and child decided whether to participate in the screening programme based on their willingness to perform a screening test in newborns. These organizations operate quite independently from hospital care in the Netherlands. Outcome of patients identified by screening (S) was compared with two cohorts of patients diagnosed clinically: one cohort born during the screening programme (non-S) and one cohort born in the 6 yrs after (post-S) the screening programme (table 1). Post-S patients were added to increase the number of patients in this follow-up study. Previous results of this follow-up study have been described elsewhere [7, 8]. From 1980-1990, clinical data were collected prospectively. Data from 1990-1997 were retrospectively collected.

After confirmation of diagnosis, patients were treated either at or in close cooperation with a $\mathrm{CF}$ centre (C) or solely at a local hospital (non-C). In CF centres, teams including paediatric pulmonologists and gastroenterologists, dieticians, physiotherapists, CF nurses, psychologists, microbiologists, and geneticists, all experienced in treating patients with $\mathrm{CF}$, provide all-round management of $\mathrm{CF}$ patients based on predefined protocols with regular follow-up. In addition, $\mathrm{CF}$ centres perform research on different aspects of CF. In local hospitals, CF care is provided by less disciplines without specialized CF clinics, and fewer CF patients are treated at local hospitals.

Allocation of treatment was left to the decision of the general paediatrician taking care of the patients at the time of diagnosis. The parents of the patients sometimes requested referral to a $\mathrm{CF}$ centre. $\mathrm{CF}$ patients who were seen once or twice a year at a $\mathrm{CF}$ centre and treated at a local hospital were considered to be treated in close cooperation with a specialized centre. The University Hospital Vrije Universiteit Amsterdam and the University Hospital Groningen ethics committees approved this study and all subjects gave informed consent.

\section{Patients}

In the present study, 92 patients were identified (table 1). Before the start of the follow-up, 10 patients died: four S patients, five non-S patients and one post$\mathrm{S}$ patient. Seventy per cent of these patients were treated solely at local hospitals. Three post-S patients treated at a specialized centre were excluded from the study because of comorbidity, including congenital heart disease, spastic tetraplegia, and severe bowel dysfunction leading to early death. During follow-up, three non-C treated patients were lost to follow-up: two $\mathrm{S}$ patients and one post-S patient. After 1990, 12 $\mathrm{CF}$ patients could be added to the present analysis. Seven patients were identified with the help of the Dutch Cystic Fibrosis Registry (four non-S and three post-S patients, $57 \%$ were treated at a CF centre) and five deceased patients (all post-S) were identified with the help of Statistics Netherlands in Voorburg. Data were retrospectively collected from the first seven patients. It was assumed that the last five patients received care at local hospitals since they were not known in the CF centres in this study. No clinical data were available from these five patients.

Diagnosis of $\mathrm{CF}$ in all patients was confirmed by a positive sweat test (sweat chloride concentration $>60 \mathrm{mmol} \cdot \mathrm{L}^{-1}$ ) performed by quantitative pilocarpine iontophoresis. Furthermore, in most patients deoxyribonucleic acid (DNA)-analysis was performed to determine the mutations involved. CF genotypes were determined by the Dept of Medical Genetics, University of Groningen. No data on mutation analysis were available from the patients who died before 1990.

Table 1.-Composition of the three patient groups

\begin{tabular}{|c|c|c|c|}
\hline & $\mathrm{S}$ & Non-S & Post-S \\
\hline Year of birth & 1973-1979 & 1973-1979 & 1979-1985 \\
\hline Number of patients & $24\left(19+5^{\#}\right)$ & 29 & 39 \\
\hline Frequency of cystic fibrosis at birth & 1:3918 & $1: 4033$ & $1: 5640$ \\
\hline Number of patients in clinical database & 24 & 29 & 34 \\
\hline \multicolumn{4}{|l|}{ Age at diagnosis months } \\
\hline Total & $1.0(0.1-120.0)$ & $18.0(0.3-220.0)$ & $22.5(0.1-89.0)$ \\
\hline Excluding patients with meconium ileus & $1.7(0.2-120.0)$ & $21.0(0.3-220.0)$ & $27.0(0.1-89.0)$ \\
\hline Excluding patients with false-negative screening tests & $0.8(0.1-43.0)$ & & \\
\hline Meconium ileus & $4(16.7 \%)$ & $2(6.9 \%)$ & $11(32.3 \%)$ \\
\hline Death before the start of study & $4(16.7 \%)$ & $5(17.2 \%)$ & $1(2.9 \%)$ \\
\hline Lost to follow-up & 2 & 0 & 1 \\
\hline Exclusion from study & 0 & 0 & 3 \\
\hline
\end{tabular}

Age data are presented as median (range). S: patients detected by screening; Non-S: patients detected by clinical symptoms; Post-S: patients born after the end of the screening programme detected by clinical symptoms. ${ }^{\text {: }}$ patients born in the screened birth cohort with false-negative screening tests; ": exclusion from study due to comorbidity. 
Forty-five $(49 \%)$ of the 92 patients were treated at or in close cooperation with a specialized centre. In the clinical follow-up, 72 patients could be included (table 1) of whom $39(54 \%)$ received centralized treatment (table 2).

\section{Outcome measures}

Survival. Patient survival was calculated as the period from birth to the end of the observation period on 1 April 1997. Patients with meconium ileus were excluded from survival analysis, they have an increased risk of dying in the first month of life, and most patients with meconium ileus were referred to a CF centre. Patients who were lost to follow-up and patients who died before the start of the study were included in the analysis until the date they were last known to be alive.

Clinical outcome. Clinical data were obtained every 6 months. For nutritional status, anthropometric variables were converted to SD scores for height and weight, by comparison with the 50th percentile for mean height and weight of Dutch children of the same age and sex [10]. Patients were classified as having pancreatic insufficiency or sufficiency according to the results of the faecal fat excretion as assessed by the Van de Kamer method and/or the presence or absence of symptoms of malabsorption responding to pancreatic enzyme supplementation. Lung function was measured using a wet $10 \mathrm{~L}$ spirometer (Lode Spirograph Type DL; Lode Instruments, Groningen, the Netherlands), or a pneumotachograph (Jaeger, Masterlab, Wuerzburg, Germany), taking the best of three manoeuvres. Inspiratory vital capacity (VC) and forced expiratory volume in one second (FEV1), expressed as a percentage of reference values based on patient height, age and sex [11], were used as parameters.

Immunoglobulins were determined by standard methods. Immunoglobulin-G (IgG) levels were used as an indicator of the severity of chronic lung infection and inflammation.

\section{Statistical analysis}

Patients with a false-negative screening test were included in the $\mathrm{S}$ group in order to perform an intention-to-screen analysis, in contrast to the previously reported analysis of this follow-up study [8]. The Chi-squared test was used to compare patient groups with respect to categorical variables. The main study interest was to examine the influence of screening on prognosis of patients with CF. Because of differences in patient management, which may also influence outcome of $\mathrm{CF}$ patients, a separate analysis of the effect of centre treatment on prognosis of patients was performed. Moreover, analyses were adjusted for differences in sex and meconium ileus between patients.

Survival. Multivariable regression analysis, based on the Cox's proportional hazard model, [12] was used to compare estimated survival between patients including the predictor variables screening, centre treatment, age at diagnosis, and sex.

Clinical outcome. Clinical outcome between patients was compared using linear mixed-effects (LME) model regression analysis [13]. The LME analysis implemented in S-Plus [14] accounts for irregularly spaced longitudinal data and different follow-up times. Screening, centre treatment, sex, and meconium ileus were used as predictor variables. The analysis of VC was also adjusted for differences in height between patients. Interaction terms with age were included to test differences in change over time of the outcome variable for various subgroups. Separate models for each clinical outcome measure, including SD scores for height and weight, FEV1 \% predicted, VC, and IgG, were fitted.

At the end of the follow-up in 1997, the eldest patients were 24 yrs of age ( $\mathrm{S}$ and non-S patients) and the youngest patients were $12 \mathrm{yrs}$ of age (post-S patients). The analysis of the clinical follow-up data was, therefore, divided into two periods: clinical outcome until, and above, 12 yrs of age. In the analysis of outcome until 12 yrs of age, the intercept

Table 2. - Comparison of the three patient groups who participated in the longitudinal linear mixed-effects (LME) analysis

\begin{tabular}{|c|c|c|c|c|}
\hline & $\mathrm{S}$ & Non-S & Post-S & p-value \\
\hline Number of patients in LME analysis & 18 & 24 & 30 & \\
\hline Male/female ratio & 1.0 & 1.0 & 1.7 & 0.61 \\
\hline Meconium ileus & $1(5.6 \%)$ & $0(0 \%)$ & $9(30.0 \%)$ & 0.07 \\
\hline Pancreatic function & & & & 0.14 \\
\hline Sufficient & $1(5.6 \%)$ & $3(12.5 \%)$ & $0(0 \%)$ & \\
\hline Insufficient & $17(94.4 \%)$ & $21(87.5 \%)$ & $30(100.0 \%)$ & \\
\hline Genotype n & 12 & 18 & 24 & 0.20 \\
\hline$\Delta \mathrm{F} 508 / \Delta \mathrm{F} 508$ & $5(41.7 \%)$ & $7(38.9 \%)$ & $15(62.5 \%)$ & \\
\hline$\Delta \mathrm{F} 508 /$ other & $5(41.7 \%)$ & $10(55.6 \%)$ & $9(37.5 \%)$ & \\
\hline Other/other & $2(16.6 \%)$ & $1(5.5 \%)$ & $0(0 \%)$ & \\
\hline Centre treatment & $10(55.6 \%)$ & $6(26.0 \%)$ & $23(76.70 \%)$ & $<0.01$ \\
\hline In survival analysis & 20 & 27 & 27 & \\
\hline
\end{tabular}

S: patients detected by screening; Non-S: patients detected by clinical symptoms; Post-S: patients born after the end of the screening programme detected by clinical symptoms. ${ }^{\#}$ : p-value for the Chi-squared test, Fisher's Exact test for expected cell size $<5$. 
or starting point was taken at the age of the first available lung function data, mostly around 6 yrs.

To explore a possible influence of genotype on clinical outcome, separate LME analyses including the variable genotype were performed.

The data are presented as differences in intercepts and slopes between patient groups. In all analyses, the significance level was taken at $\mathrm{p}<0.05$.

\section{Results}

During the follow-up, 24 screened and 68 nonscreened $\mathrm{CF}$ patients were identified (table 1). Frequency of $\mathrm{CF}$ at birth was similar in the $\mathrm{S}$ and non-S groups, but was lower in the post-S group. Age at diagnosis and number of patients with meconium ileus was highest in the post-S group.

\section{Survival}

Analysis of survival was performed in 74 patients, excluding 18 patients with meconium ileus or comorbidity.

Influence of screening. After adjustment for age at diagnosis, sex, and centre treatment, the $\mathrm{S}$ group seemed to have a better survival throughout follow-up than the non-S and post-S groups (fig. 1). The relative risk (RR) of dying for the $\mathrm{S}$ group was $0.43(95 \%$ confidence interval (CI) $0.13-1.38, \mathrm{p}=0.16)$ in comparison with the non-S group, and $0.35(95 \%$ CI 0.09-1.41, $\mathrm{p}=0.14)$ in comparison with the post-S group. As compared with the non-S group, the RR of dying for the post-S group was 1.23 (95\% CI 0.42-3.60, $\mathrm{p}=0.70$ ).

Influence of centre treatment. After adjustment for screening, age at diagnosis, and sex, the $\mathrm{C}$ group had a significantly better survival during total follow-up than

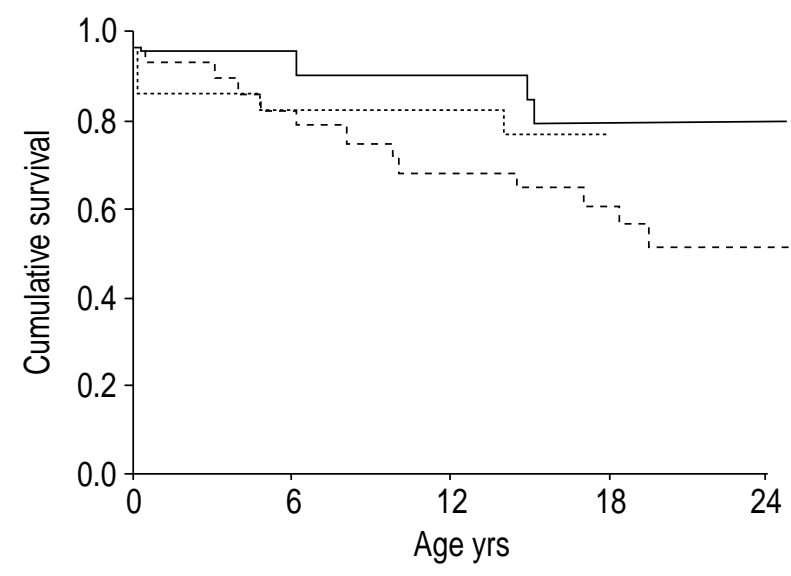

Fig. 1.-Estimated cumulative survival of patients detected by screening $\left(\mathrm{S} ;-{ }_{-}\right)$and those detected clinically; born between 1973 and 1979 (non-S; ------) and between 1979 and 1986 (post-S; .........), excluding all patients with meconium ileus. At the end of the follow-up, the eldest patients were 24 yrs of age in the $\mathrm{S}$ and non-S groups and $18 \mathrm{yrs}$ of age in the post-S group. the non-C group (fig. 2). The RR of dying for patients from the $\mathrm{C}$ group compared with patients from the non-C group was $0.18(95 \%$ CI $0.05-0.57, \mathrm{p}<0.01)$.

\section{Clinical outcome}

Longitudinal clinical evaluations were performed in 72 patients: $18 \mathrm{~S}, 24$ non-S, and 30 post-S patients (table 2). From the 72 patients, $39(54 \%)$ received centre care. Patients with meconium ileus were included in this analysis. Characteristics of patients participating in the longitudinal analysis are compared in table 2. The number of patients treated at a specialized centre was significantly higher in the $\mathrm{S}$ group than in the non-S group. The post-S group received more centre care than the $S$ group.

Observed values throughout total follow-up from FEV1 \% pred in the S, non-S and post-S patients are shown in figure 3 . In addition, observed values from SD weight and FEV1 \% pred in the $\mathrm{C}$ and non-C patients are presented in figures 4 and 5. In these figures, no adjustment is made for the influence of the several predictor variables used in the LME analyses, such as screening, centre treatment, sex, and meconium ileus.

Influence of screening. Analysis of outcome until $12 \mathrm{yrs}$ of age. Until the age of $12 \mathrm{yrs}, \mathrm{S}$ patients showed a tendency towards better SD scores for height and weight than non-S patients. Difference in SD weight at the age of 6 yrs between $S$ and non-S groups was $0.52, \mathrm{p}=0.06$ (table 3 ). As a result of a higher increase of height over time in the non$\mathrm{S}$ group, differences in height at the end of this period between these groups were much smaller. No significant differences in nutritional status until the age of 12 yrs were found between the $S$ and post-S groups. However, in comparison with the non-S group, the post-S group was significantly heavier at the age of 6 yrs (difference in intercept of SD weight: $0.77, \mathrm{p}<0.01$; table 3 ).

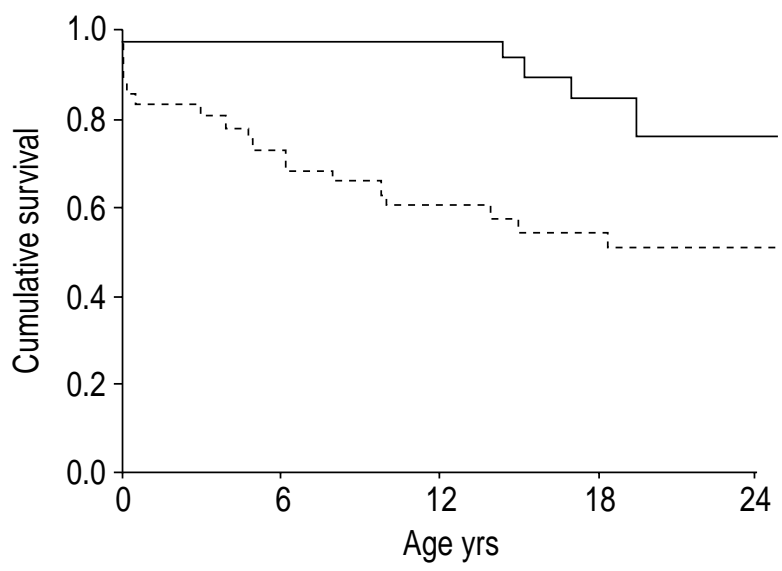

Fig. 2.-Estimated cumulative survival of patients treated at or in close cooperation with a specialized centre $(\mathrm{C} ;-)$ and patients treated solely at a local hospital (non-C; ------), excluding all patients with meconium ileus. At the end of the follow-up, the eldest patients were 24 yrs of age. 

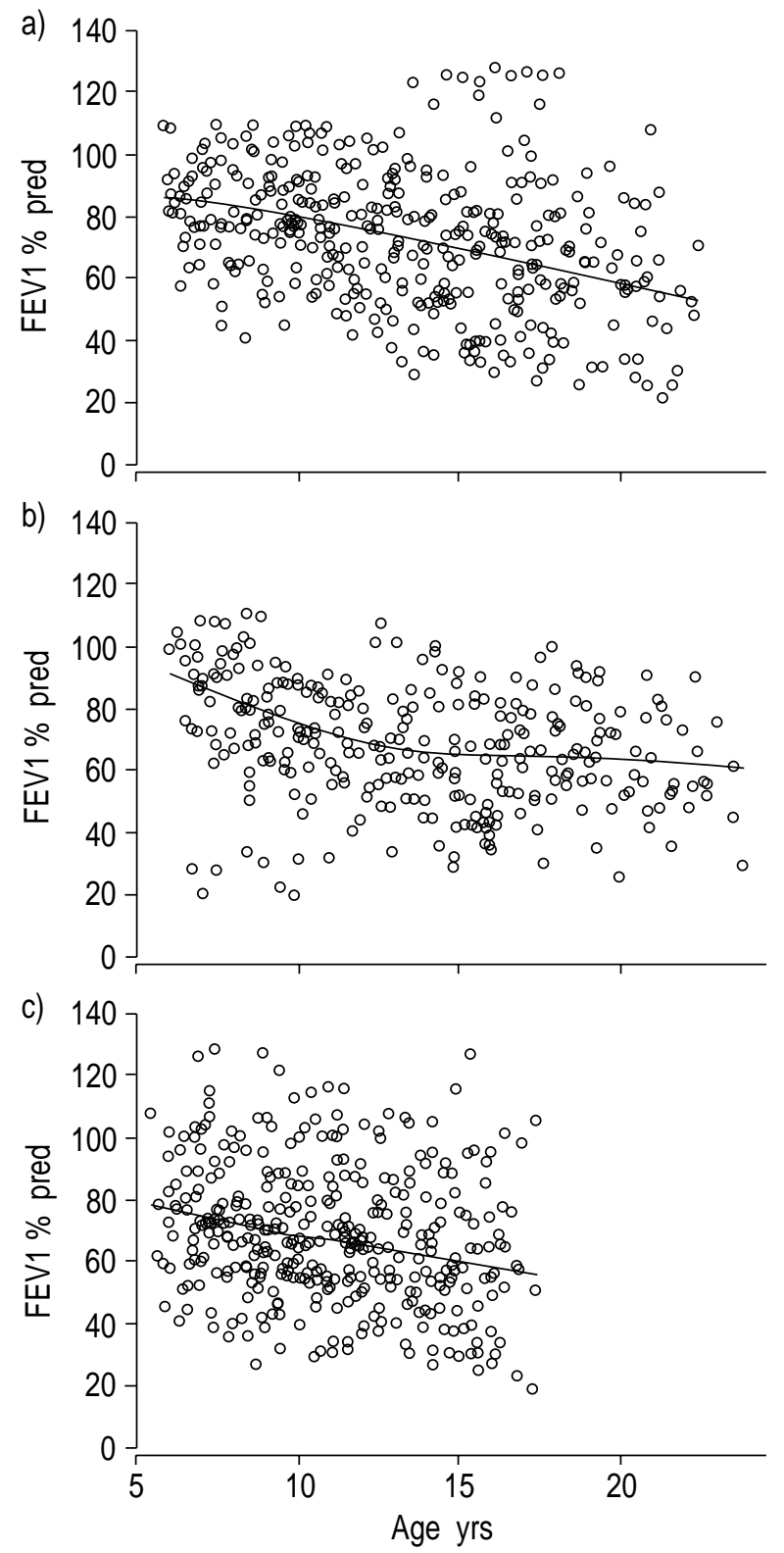

Fig. 3.-Observed values of forced expiratory volume in one second (FEV1 \% pred) throughout the total follow-up period in patients: a) detected by screening ( $\mathrm{S}, \mathrm{n}=18)$, and patients detected clinically; b) born between 1973 and 1979 (non-S, $n=24)$; and c) born between 1979 and 1986 (post-S, n=30). Each circle represents a value from an individual patient. Each patient can be represented by more than one circle. ——: robust scatterplot smoother (Lo(w)ess).

At the age of $6 \mathrm{yrs}$, the $\mathrm{S}$ group seemed to have better lung function parameters than the non-S and post-S groups. The post-S group showed the worst lung function at this age.

As expected, all patients showed a decline in FEV1 $\%$ pred throughout the observation period. However, the change in FEV1 over time was significantly different between the $\mathrm{S}$ and non-S groups, favouring the $\mathrm{S}$ group (difference in slope $2.74 \%$ pred, $\mathrm{p}<0.05$ ), and between the post-S and non-S groups, favouring the post-S group (difference in slope $2.80 \%$ pred,
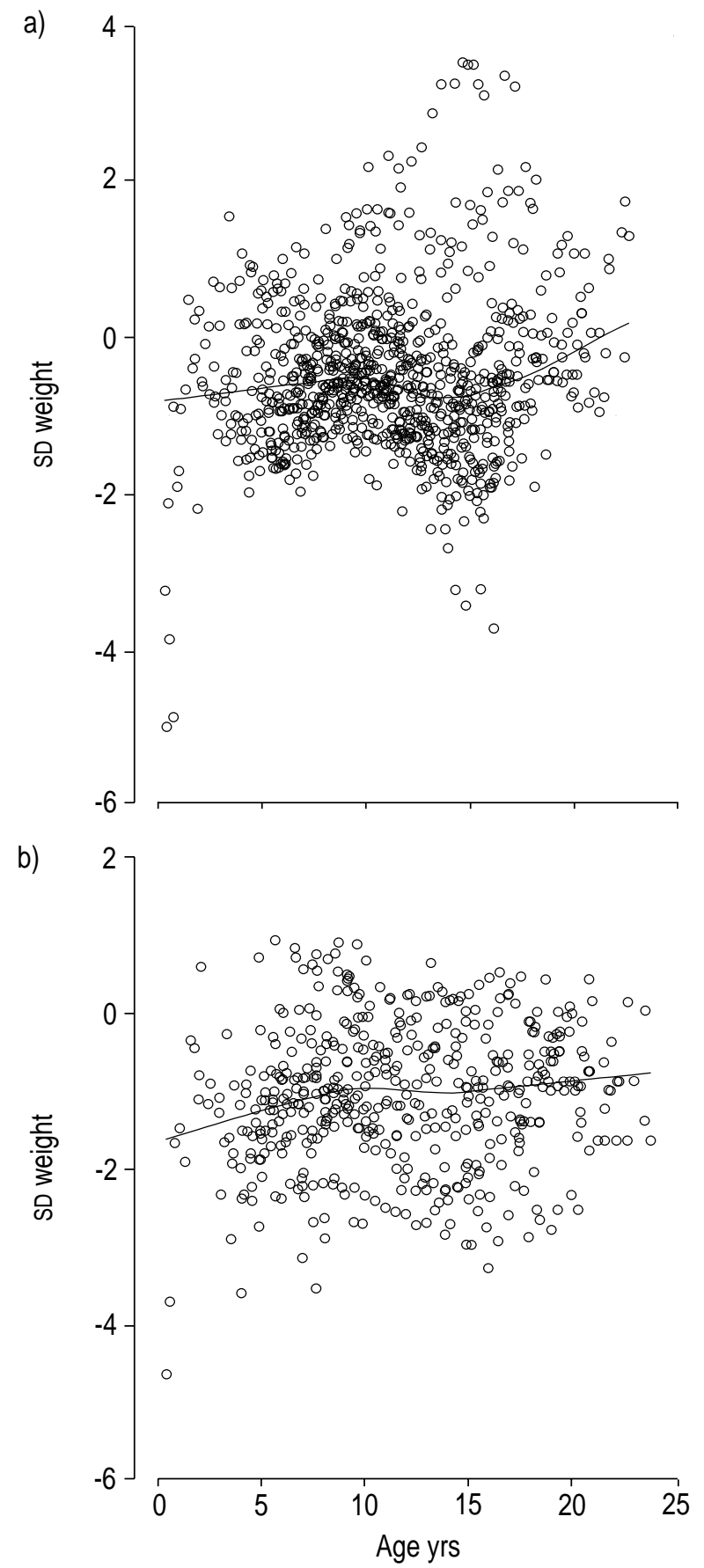

Fig. 4.-Observed values of SD weight throughout the total follow-up period in patients treated a) at a specialized centre $(C$, $\mathrm{n}=39$ ), and b) solely at the local hospital (non-C, $n=33$ ). Each circle represents a value from an individual patient. Each patient can be represented by more than one circle. - : robust scatterplot smoother (Lo(w)ess).

$\mathrm{p}<0.05$ ) (table 3 ). The change in FEV1 over time in the $\mathrm{S}$ group was not different from that in the post-S group. The $\mathrm{S}$ and post-S groups tended to have a higher increase in $\mathrm{VC}$ over time than the non-S group.

In this analysis, the $\mathrm{S}$ group had significantly lower IgG levels than the non-S group (difference in 

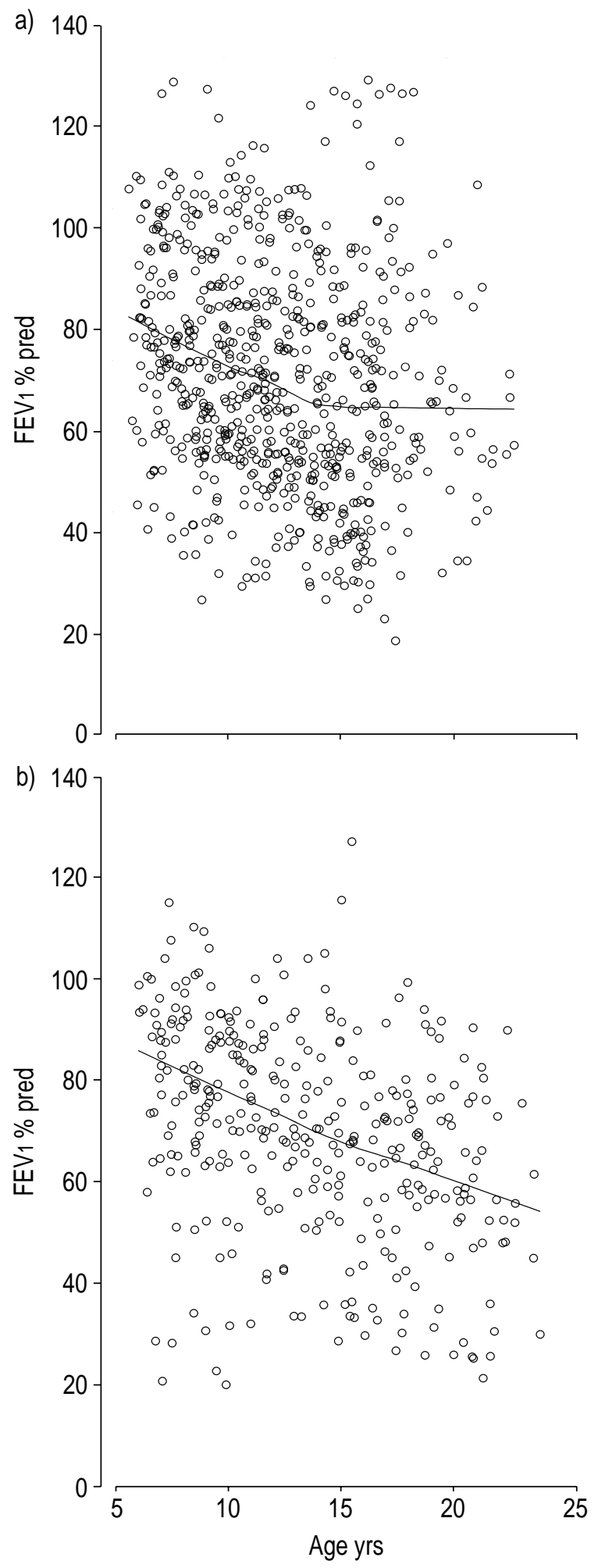

Fig. 5.-Observed values of forced expiratory volume in one second (FEV1 \% pred) throughout the total follow-up period in a) patients treated at a specialized centre $(C, n=39)$ and b) patients treated solely at the local hospital (non-C, $n=33$ ). Each circle represents a value from an individual patient. Each patient can be represented by more than one circle. — : robust scatterplot smoother (=lowest).

intercept $-473.69 \mathrm{mg} \cdot \mathrm{dL}^{-1}, \mathrm{p}<0.01$; table 3). Levels of $\mathrm{IgG}$ were similar in patients from the $\mathrm{S}$ and post-S groups, but the post-S group had significantly lower IgG levels than the non-S group (difference in intercept $-453.04 \mathrm{mg} \cdot \mathrm{dL}^{-1}, \mathrm{p}<0.01$; table 3 ).

Analysis of outcome above 12 yrs of age. After the age of 18, final height is expected to be achieved among patients in the follow-up. Therefore, the analysis of nutritional status after the age of $12 \mathrm{yrs}$ was performed until the age of 18 yrs. Differences in height and weight between the $\mathrm{S}$ and non-S groups were smaller in patients $>12$ yrs of age than $<12$ yrs of age and were statistically not significant. In addition, no significant differences in nutritional status between either the $\mathrm{S}$ and post-S groups or the post-S and non-S groups were found.

The $\mathrm{S}$ group tended to have overall better lung function parameters than the non-S and post-S groups. Average values of $\mathrm{VC}$ at the age of $12 \mathrm{yrs}$ in the $\mathrm{S}$ group were significantly higher than in the non-S group (difference in intercept $362.79 \mathrm{~mL}, \mathrm{p}=0.03$; table 4). In addition, a tendency towards higher values of FEV1\% pred was observed in the $\mathrm{S}$ group. Differences in the two lung function parameters between the $\mathrm{S}$ and post-S groups were not significant, but the $\mathrm{S}$ group tended to have a higher increase of VC over time after the age of 12 yrs than the post-S group. At the age of $12 \mathrm{yrs}$, patients from the post-S group tended to have better lung function parameters than patients from the non-S group, but with increasing age the changes in lung function over time were similar.

Differences in the IgG levels between the $\mathrm{S}$ and non$S$ groups in patients $<12$ yrs old, in favour of the screened patients, persisted after the age of 12 yrs but were no longer significant. The IgG levels throughout this observation period were similar in the $S$ and post$\mathrm{S}$ groups. Although the $\mathrm{IgG}$ values appeared to be lower in the post-S group, differences in IgG levels between post-S and non-S groups were not significant in this analysis.

Influence of centre treatment. Analysis of outcome until $12 \mathrm{yrs}$ of age. Observed values of weight were higher in the $\mathrm{C}$ group than in the non-C group (fig. 4). Similar results were observed for SD height. Nevertheless, in the LME analysis, the increase of both nutritional parameters over time was similar in both groups, and differences in intercept and slope from SD scores for height and weight were statistically not significant. Until the age of $12 \mathrm{yrs}$, FEV1 declined in both groups over time (fig. 5). This decline was slightly, but not significantly, less in the $\mathrm{C}$ group. A greater increase in VC over time was found in the $\mathrm{C}$ group, but differences in slopes of $\mathrm{VC}$ between $\mathrm{C}$ and non- $\mathrm{C}$ groups were statistically not significant.

IgG levels at the age of 6 yrs were found to be lower in the $\mathrm{C}$ group than in the non-C group. Until the age of 12 yrs, both groups showed an increase in $\mathrm{IgG}$ over time. This increase was slightly, but not significantly, higher in the $\mathrm{C}$ group.

Analysis of outcome above 12 yrs of age. Although centre-treated patients seemed heavier and taller than 
Table 3. - Comparison of clinical outcome until 12 yrs between screened and nonscreened patients by linear mixed-effects (LME) analysis (with intercept at age 6 yrs) expressed as mean difference between groups

\begin{tabular}{|c|c|c|c|c|c|}
\hline Variable & Comparison & $\begin{array}{l}\text { Differences } \\
\text { in intercept }\end{array}$ & $95 \% \mathrm{CI}$ & $\begin{array}{l}\text { Differences } \\
\text { in slope }\end{array}$ & $95 \% \mathrm{CI}$ \\
\hline \multirow[t]{3}{*}{ SD height } & $\mathrm{S}$ versus non-S & 0.42 & $-0.20-1.04$ & -0.04 & $-0.12-0.04$ \\
\hline & S versus post-S & -0.17 & $-0.76-0.42$ & -0.06 & $-0.13-0.01$ \\
\hline & Post-S versus non-S & 0.59 & $-0.02-1.19$ & 0.02 & $-0.02-0.06$ \\
\hline \multirow{3}{*}{ SD weight } & S versus non-S & 0.52 & $-0.01-1.05$ & 0.01 & $-0.10-0.10$ \\
\hline & $\mathrm{S}$ versus post-S & -0.25 & $-0.92-0.43$ & -0.05 & $-0.13-0.03$ \\
\hline & Post-S versus non-S & $0.77^{*}$ & $0.25-1.29$ & 0.06 & $-0.03-0.15$ \\
\hline \multirow[t]{3}{*}{ FEV1 \% pred } & S versus non-S & 2.64 & $-12.20-17.48$ & $2.74 *$ & $0.06-5.43$ \\
\hline & S versus post-S & 5.15 & $-7.90-18.20$ & -0.06 & $-2.37-2.25$ \\
\hline & Post-S versus non-S & -2.51 & $-2.37-2.25$ & $2.80 *$ & $0.07-5.53$ \\
\hline \multirow[t]{3}{*}{$\mathrm{VC} \mathrm{mL}$} & $\mathrm{S}$ versus non-S & 21.13 & $-169.13-211.39$ & 44.89 & $-16.26-106.04$ \\
\hline & S versus post-S & 123.32 & $-43.33-166.66$ & -2.12 & $-56.24-51.99$ \\
\hline & Post-S versus non-S & -102.19 & $-289.39-85.01$ & 47.01 & $-15.12-109.14$ \\
\hline \multirow{3}{*}{$\mathrm{IgG} \mathrm{mg} \cdot \mathrm{dL}^{-1}$} & S versus non-S & -473.69 & $-799.12-148.25$ & -59.05 & $-127.10-9.01$ \\
\hline & $\mathrm{S}$ versus post-S & -20.65 & $-331.51-290.21$ & -5.80 & $-67.31-57.15$ \\
\hline & Post-S versus non-S & -453.04 & $-782.69-123.40$ & -53.23 & $-122.63-16.17$ \\
\hline
\end{tabular}

CI: confidence interval; S: patients detected by screening; Non-S: patients detected by clinical symptoms; Post-S: patients born after the end of the screening programme detected by clinical symptoms; SD height: standard deviation score for height; SD weight: standard deviation score for weight; FEV1 \% pred: forced expiratory volume in one second, expressed as a percentage of a predicted values; VC: vital capacity; IgG: immunoglobulin-G. The slope represents the estimated average change of a clinical parameter over time. *: $\mathrm{p}<0.05$.

the noncentre-treated patients at the age of $12 \mathrm{yrs}$ (fig. 4), differences in height and weight did not reach significance. The increase of both height and weight over time was similar in both groups.

After 12 years of age, the decline in FEV1\% pred and the increase in VC over time tended to be in favour of the $\mathrm{C}$ group. Figure 5 shows that after 12 yrs of age FEV1 continues to decline in the non-C group, whereas average observed values of FEV1 stay rather constant over time in the in the $\mathrm{C}$ group In addition, the observed values of $\mathrm{VC}$ were much higher in the $\mathrm{C}$ group than in the non-C group. Nevertheless, in the LME analysis, the differences in intercept and slope of FEV1 and VC were not significant for centre-treated and noncentre-treated patients.

Due to the slightly higher increase in $\mathrm{IgG}$ over time before the age of $12 \mathrm{yrs}$, the $\mathrm{C}$ group showed, in patients $>12$ yrs of age, a tendency towards higher $\mathrm{IgG}$ levels than the non-C group. However, the differences in both intercept and slope of $\operatorname{IgG}$ between the two groups were statistically not significant.

Table 4. - Comparison of clinical outcome above $12 \mathrm{yrs}$ of age between screened and nonscreened patients by linear mixed-effects (LME) analysis (with intercept at age $12 \mathrm{yrs}$ ) expressed as mean difference between groups

\begin{tabular}{|c|c|c|c|c|c|}
\hline Variable & Comparison & $\begin{array}{l}\text { Differences } \\
\text { in intercept }\end{array}$ & $95 \% \mathrm{CI}$ & $\begin{array}{l}\text { Differences } \\
\text { in slope }\end{array}$ & $95 \% \mathrm{CI}$ \\
\hline \multirow[t]{3}{*}{ SD height $\#$} & $\mathrm{~S}$ versus non-S & -0.09 & $-0.83-0.65$ & -0.01 & $-0.10-0.10$ \\
\hline & S versus post-S & -0.26 & $-0.95-0.43$ & 0.04 & $-0.07-0.15$ \\
\hline & Post-S versus non-S & 0.17 & $-0.57-0.91$ & -0.05 & $-0.17-0.08$ \\
\hline \multirow[t]{3}{*}{ SD weight ${ }^{\#}$} & $\mathrm{~S}$ versus non-S & 0.17 & $-0.57-0.91$ & -0.04 & $-0.18-0.10$ \\
\hline & S versus post-S & -0.03 & $-0.72-0.66$ & 0.03 & $-0.11-0.17$ \\
\hline & Post-S versus non-S & 0.20 & $-0.55-0.95$ & -0.08 & $-0.24-0.12$ \\
\hline \multirow[t]{3}{*}{ FEV1 \% pred } & $\mathrm{S}$ versus non-S & 8.60 & $-6.00-23.20$ & 0.10 & $-1.97-2.17$ \\
\hline & $\mathrm{S}$ versus post-S & 1.54 & $-12.00-15.08$ & -0.13 & $-2.50-2.23$ \\
\hline & Post-S versus non-S & 7.06 & $-2.50-2.23$ & 0.23 & $-2.43-2.89$ \\
\hline \multirow[t]{3}{*}{$\mathrm{VC} \mathrm{mL}$} & S versus non-S & $362.79 *$ & $43.41-682.17$ & -3.25 & $-96.31-89.81$ \\
\hline & $\mathrm{S}$ versus post-S & 14.65 & $-20.23-30.11$ & 41.53 & $-155.15-62.34$ \\
\hline & Post-S versus non-S & 348.14 & $3.04-693.37$ & -44.78 & $-158.07-68.51$ \\
\hline \multirow[t]{3}{*}{$\mathrm{IgG} \mathrm{mg} \cdot \mathrm{dL}^{-1}$} & S versus non-S & -328.31 & $-734.74-78.11$ & -15.19 & $-96.63-66.25$ \\
\hline & S versus post-S & -62.45 & $-459.57-334.66$ & 1.40 & $-98.84-101.65$ \\
\hline & Post-S versus non-S & -265.87 & $-722.05-190.32$ & -16.60 & $-123.69-90.50$ \\
\hline
\end{tabular}

CI: confidence interval; S: patients detected by screening; Non-S: patients detected by clinical symptoms; Post-S: patients born after the end of the screening programme detected by clinical symptoms; SD height: standard deviation score for height; SD weight: standard deviation score for weight; FEV1 \% pred: fiorced expiratory volume in one second, expressed as a percentage of a predicted values; VC: vital capacity; IgG: immunoglobulin-G. The slope represents the estimated average change of a clinical parameter over time. ${ }^{\#}$ : Calculated for the ages $12-18 \mathrm{yrs} ; *: \mathrm{p}<0.05$. 
Influence of genotype on the linear mixed-effects analyses of clinical outcome of patients with cystic fibrosis

Data on genotype were available from 55 patients. Genotype did not significantly affect the influence of screening in the LME analyses of clinical outcome. Also, the influence of centre treatment on clinical outcome was not influenced by differences in genotype between patients, except for the parameter IgG. The LME analysis of outcome above 12 yrs of age, including the variable genotype, showed a difference in $\mathrm{IgG}$ between the $\mathrm{C}$ and non-C groups, with respect to the intercept of $-0.11 \mathrm{mg} \cdot \mathrm{dL}^{-1}$ and the slope of $+8.73 \mathrm{mg} \cdot \mathrm{dL}^{-1}$. In contrast, the same LME analysis without the variable genotype showed a difference between the $\mathrm{C}$ and non- $\mathrm{C}$ groups in intercept from $\mathrm{IgG}$ of $+99.47 \mathrm{mg} \cdot \mathrm{dL}^{-1}$ and a difference in slope from $\mathrm{IgG}$ of $-13.94 \mathrm{mg} \cdot \mathrm{dL}^{-1}$. However, this difference was, like the other differences, statistically not significant.

\section{Discussion}

\section{Neonatal screening}

This study demonstrates the long-term pulmonary benefits of neonatal screening for $\mathrm{CF}$. S patients showed a smaller decline in FEV1 \% pred, mainly before 12 yrs of age, together with higher levels of VC than non-S patients. In addition, $S$ patients had significantly lower IgG levels until 12 yrs of age than non-S patients. A better preservation of lung function in the $S$ group was found, despite an overall better clinical condition in the non-S group in patients $>12$ yrs of age, due to a greater loss of severe patients who died at a young age in the non-S group. Improved lung function associated with neonatal screening for $\mathrm{CF}$ has also been reported in a recent study from Australia [6]. S patients tended to have a longer survival into adulthood than non-S patients (fig. 1).

Although the $\mathrm{S}$ group appeared to be heavier and taller than the non-S group, differences in nutritional status were not significant. A greater catch-up growth after diagnosis, as well as an overall better clinical condition after the age of 12 yrs in the non-S group, may be possible explanations for the similar nutritional status. Early nutritional benefits of neonatal screening have also been found in the randomized, controlled trial from Wisconsin [3]. Significantly, beneficial effects of neonatal screening on clinical outcome and survival could not be found in the comparison between $\mathrm{S}$ patients and the younger post$\mathrm{S}$ patients. However, this comparison was biased for the following reasons. First, $\mathrm{CF}$ patients born later are likely to have a better prognosis than $\mathrm{CF}$ patients born earlier $[15,16]$. In the present study, the post-S group had a significantly better clinical outcome until 12 yrs of age than the non-S group. After 1980, CF patients received better pancreatic enzyme replacement therapy and were no longer treated with a low fat diet. Despite better nutritional management from time of diagnosis, the outcome of the post-S group was not significantly different from that of the $\mathrm{S}$ group. Moreover, $\mathrm{S}$ patients seemed to have a better preservation of lung function than post-S patients. These results indicate that early intervention through neonatal screening can have long-term pulmonary benefits that are superior to the recognized beneficial effects of a good nutritional status on lung function [17]. Secondly, despite a longer follow-up than in a previous report [8], the frequency of CF at birth in this group was relatively low and it is suspected that the post-S group was (still) incomplete. It is speculated that in this group, patients died at a young age prior to diagnosis of CF because of the high age at diagnosis and the proportionally high number of patients with meconium ileus. Incomplete ascertainment is likely to result in biased comparisons of clinical outcome and survival.

\section{Centre treatment}

Treatment at a specialized centre improved longterm survival of patients with CF (fig. 2). The RR of dying for the $\mathrm{C}$ group compared with the non-C group was $0.18(95 \%$ CI $0.05-0.57, \mathrm{p}<0.01)$. Studies from Denmark [18] and Australia [19] have also shown longer survival in $\mathrm{CF}$ patients receiving care at a specialized centre. Over time, treatment was improving, as more and more patients were being treated at specialized centres. This may have resulted in a biased comparison between $\mathrm{C}$ and non-C patients. However, the differences in clinical outcome and survival between $\mathrm{C}$ and non- $\mathrm{C}$ groups were adjusted for the number of patients born during and after the screening programme in each group.

Although not statistically significant, centre-treated patients seemed to be heavier and taller and tended to have a better preservation of lung function in this 17yr follow-up study than patients without centralized care. Since differences in nutritional status and lung function between treatment groups were in the same direction, they are, therefore, likely to be real and not due to chance. Moreover, differences in nutritional status and lung function did not change significantly after adjustment for genotype.

IgG levels were slightly, but not significantly, higher in the $\mathrm{C}$ group than in the non- $\mathrm{C}$ group after the age of 12 yrs. Serum immunoglobulin levels often rise after chronic colonization with Pseudomonas auruginosa in CF [20]. The percentage of patients with pseudomonas colonization was also slightly, but not significantly, higher among $\mathrm{C}$ patients: $57.9 \%$ in the $\mathrm{C}$ group and $51.6 \%$ in the non-C group, $\mathrm{p}=0.60$. The observed differences in $\mathrm{IgG}$ above 12 yrs of age may be caused by differences in genotype between patients. Severe genotypes are often associated with a higher colonization rate with $P$. aeruginosa than mild genotypes [21], which may lead to higher IgG levels. The $\mathrm{C}$ group contained more patients with a severe mutation than the non-C group. After adjustment for genotype, similar IgG levels above 12 yrs of age in both groups were found.

The results of the comparison of clinical outcome 
between $\mathrm{C}$ and non- $\mathrm{C}$ patients may have been affected by differences in survival. Before the age of $12 \mathrm{yrs}$, none of the patients from the $\mathrm{C}$ group died, in contrast with the non-C group in whom 17 out of 47 patients $(36 \%)$ died. Overall, clinical condition of non$\mathrm{C}$ patients was better in the analysis in patients $>12$ yrs old than $<12$ yrs old, probably due to the absence of patients with a severe clinical expression who died at a young age. The selection bias introduced by survival of the fittest may be an explanation for the nonsignificant differences found in the comparison of long-term clinical outcome between the $\mathrm{C}$ and non- $\mathrm{C}$ groups.

Although this study was not randomized in design, the allocation of patient groups was nonselective. Complete ascertainment of the $\mathrm{S}$ and non-S groups is probable as they were comparable in size and frequency of $\mathrm{CF}$ at birth (table 1). Age at diagnosis in the non-S group did not differ significantly from that of patients in the national Dutch Cystic Fibrosis Registry [22]. However, the number of patients who received centre care was significantly greater in the $\mathrm{S}$ group than in the non-S group (table 2). Centre treatment was associated with an improved survival of patients with CF in the present study (fig. 2). Therefore, the analyses of survival and clinical outcome were adjusted for centre treatment. In addition, comparison of clinical outcome was adjusted for the possible confounding variables sex and meconium ileus. Furthermore, the analyses did not change significantly after adjustment for genotype [23]. Therefore, differences in outcome between screened and nonscreened patients cannot be explained by differences in centre treatment, sex, meconium ileus or genotype, and selection bias is highly improbable.

The LME model regression analysis applied in this study to compare clinical outcome between patients, is considered as the statistical technique of choice in clinical trials involving the longitudinal analysis of lung function data [24]. The advantage of this methodology is that estimates of average changes can be computed even when individual subjects have had variable length of follow-up and timing of observations. Moreover, covariables can be incorporated in the analysis. Selection bias can be prevented with this type of analysis.

Although differences in prognosis between $\mathrm{S}$ and non-S patients and $\mathrm{C}$ and non-C patients observed in the present study were in the same direction in favour of the $\mathrm{S}$ and $\mathrm{C}$ groups, only a few were statistically significant. However, the statistical power of the present study was too low, which may lead to falsenegative results. Recently, it has been calculated that studies of this kind need $\geqslant 66$ patients in each patient group to detect a $10 \%$ difference in an outcome measure such as FEV1 [25].

The use of the meconium test led to five patients from the $\mathrm{S}$ group being undetected. These patients were included in the $\mathrm{S}$ group in the present report, in order to perform an intention-to-screen analysis. However, present screening tests for $\mathrm{CF}$ possess sensitivities of $\geqslant 97 \%[26,27]$.

\section{Conclusions}

The results of the present longitudinal study show that neonatal screening for cystic fibrosis lead to pulmonary benefits in adulthood. Moreover, screened patients probably have a longer survival than nonscreened patients. The statistically significant differences in this small sized study although few in number, suggest that while selection bias is improbable early diagnosis by screening and early treatment leads to substantial clinical benefit for patients with cystic fibrosis. A striking finding was the tendency towards better lung function parameters in screened patients born earlier, compared to the nonscreened patients born later, despite better nutritional management in the younger cohort. Centralized treatment resulted in an improved long-term survival of patients with cystic fibrosis. The present findings imply that management of all patients with cystic fibrosis should be carried out at, or in close cooperation with, a specialized centre, immediately after a diagnosis is made by neonatal screening.

\footnotetext{
Acknowledgements. The authors thank G. Slingerland for helpful assistance in the collection of data and $\mathrm{G}$. te Meerman for helpful discussions on the statistical analysis. The help of the Dutch Cystic Fibrosis registration and Statistics Netherlands in Voorburg for finding all patients from the area is gratefully acknowledged. The authors are grateful to all patients, paediatricians, and pulmonologists without whom this study would not have been possible.
}

\section{References}

1. Armstrong D, Grimwood K, Carzino R. Lower respiratory infection and inflammation in infants with newly diagnosed cystic fibrosis. BMJ 1995; 310 : 1571-1572.

2. Armstrong DS, Grimwood K, Carlin JB, et al. Lower airway inflammation in infants and young children with cystic fibrosis. Am J Respir Crit Care Med 1997; 156: 1197-1204.

3. Farrell PM, Kosorok MR, Laxova A, et al. Nutritional benefits of neonatal screening for cystic fibrosis. N Engl J Med 1997; 337: 963-969.

4. Chatfield S, Owen G, Ryley HC, et al. Neonatal screening for cystic fibrosis in Wales and the West Midlands: clinical assessment after five years of screening. Arch Dis Child 1991; 66: 29-33.

5. Mérelle ME, Nagelkerke AF, Lees CM, Dezateux C. Newborn screening for cystic fibrosis. The Cochrane Library 1999; Issue 3 (Update Software) Oxford.

6. Waters DL, Wilcken B, Irwig L, et al. Clinical outcomes of newborn screening for cystic fibrosis. Arch Dis Child Fetal Neonatal Ed 1999; 80: F1-F7.

7. Dankert-Roelse JE, te Meerman GJ, Martijn A, ten Kate LP, Knol K. Survival and clinical outcome in patients with cystic fibrosis, with or without neonatal screening. J Pediatr 1989; 114: 362-367.

8. Dankert-Roelse JE, te Meerman GJ. Long term prognosis of patients with cystic fibrosis in relation 
to early detection by neonatal screening and treatment in a cystic fibrosis centre. Thorax 1995; 50: 712-718.

9. Ten Kate LP, Feenstra-de Gooyer J, Ploeg-de Groot G, Gouw WL, Anders BJPA. Should we screen all newborns for cystic fibrosis? Int J Epidemiol 1978; 7 : 323-330

10. Gerver WJM, de Bruin R. Paediatric morphometrics A reference manual, 1st ed. Wetenschappelijke uitgeverij Bunge, Utrecht, The Netherlands, 1996; 35-45.

11. Zapletal A, Samenek M, Paul T. Lung function in children and adolescents. Methods and reference values. In: Zapletal A, ed. Progression in respiratory research. Kargel, Basel. 1987; 114-218.

12. Hayllar KM, Williams SGJ, Wise AE, et al. A prognostic model for the prediction of survival in cystic fibrosis. Thorax 1997; 52: 313-317.

13. Laird NM, Ware JH. Random-effects models for longitudinal data. Biometrics 1982; 38: 963-974.

14. Pinheiro JC, Bates DM. Mixed effect models in S and Splus. New York, Springer Verlag Inc., 2000.

15. FitzSimmons SC. The changing epidemiology of cystic fibrosis. J Pediatr 1993; 122: 1-9.

16. Elborn JS, Shale DJ, Britton JR. Cystic fibrosis: Current survival and population estimates to the year 2000. Thorax 1991; 46: 881-885.

17. Borowitz D. The interrelationship of nutrition and pulmonary function in patients with cystic fibrosis. Curr Opin Pulm Med 1996; 2: 457-461.

18. Nielsen OH, Schiøtz PO. Cystic fibrosis in Denmark in the period 1945-1981. Evaluation of centralized treatment. Acta Paediatr Scand 1982; 301: Suppl., 107-119.

19. Hill DJS, Martin AJ, Davidson GP, Smith GS.
Survival of cystic fibrosis patients in South Australia. Med J Aust 1985; 143: 230-232.

20. Høiby N. Haemophilus influenza, Staphylococcus aureus, Pseudomonas cepacia, and Pseudomonas aeruginosa in patients with cystic fibrosis. Chest 1988; 94: 97-102.

21. Kubesch P, Dörk T, Wulbrand U, et al. Genetic determinants of airways' colonisation with Pseudomonas Aeruginosa in cystic fibrosis. Lancet 1993; 341: 189-193.

22. Möller LVM, Dankert-Roelse JE, Collée JM, van Alphen L, Dankert J. The general approach to cystic fibrosis pulmonary infection in the Netherlands. In: Bauernfeind A, Marks MI, Strandvik B, eds. Cystic fibrosis pulmonary infection - lessons from around the world. Basel, Birkhauser-Verlag, 1996; 279-291.

23. Dean M, Santis G. Heterogeneity in the severity of cystic fibrosis and the role of CFTR gene mutations. Hum Genet 1994; 93: 364-368.

24. Edwards LJ. Modern statistical techniques for the analysis of longitudinal data in biomedical research. Pediatr Pulmonol 2000; 30: 330-344.

25. Cheng K, Smyth RL, Motley J, O'Hea U, Ashby D. Randomized controlled trials in cystic fibrosis (19661997) categorized by time, design, and intervention. Pediatr Pulmonol 2000; 29: 1-7.

26. Dankert-Roelse JE. Neonatal screening. In: Dodge JA, Brock DJH, Widdicombe JH, eds. Cystic fibrosis Current Topics. Chichester, John Wiley \& Sons Ltd, 1993; 303-317.

27. Murray J, Cuckle H, Taylor G, Littlewood J, Hewison J. Screening for cystic fibrosis. Health Technol Assessment 1999; 3 : 8. 